\title{
Differentiation between activity of digestive enzymes of Brachionus calyciflorus and extracellular enzymes of its epizooic bacteria
}

\author{
Martina ŠTROJSOVÁ ${ }^{1,2) *}$ and Wilko H. AHLRICHS ${ }^{3)}$ \\ ${ }^{1)}$ University of South Bohemia, Faculty of Science, Branišovská 31, CZ-370 05 České Budějovice, Czech Republic \\ ${ }^{2)}$ Biology Centre AS CR, Institute of Hydrobiology, Na Sádkách 7, CZ-370 05 České Budějovice, Czech Republic \\ ${ }^{3)}$ Carl von Ossietzky Universität, Department of Biology and Environmental Sciences, D-26111 Oldenburg, Germany \\ *e-mail corresponding author: martina.strojsova@seznam.cz
}

\begin{abstract}
The rotifer Brachionus calyciflorus was examined by scanning electron microscopy (SEM) for surface-attached, i.e. epizootic, bacteria to ascertain their specific localization and thus find out if we could discern between rotifer and bacterial enzyme activity. The lorica of $\mathrm{B}$. calyciflorus was colonized by one distinct type of bacteria, which originated from the algal culture used for rotifer feeding. The corona, posterior epidermis and foot of all inspected individuals were always without attached bacteria. The density of the attached bacteria was higher with the increasing age of $\mathrm{B}$. calyciflorus: while young individuals were colonized by $\sim$ tens of bacterial cells, older ones had on average hundreds to thousands of attached bacteria. We hypothesize that epizooic bacteria may produce the ectoenzymes phosphatases and $\beta$ - $N$-acetylhexosaminidases on the lorica, but not on the corona of $\mathrm{B}$. calyciflorus. Since enzyme activities of epizooic bacteria may influence the values and interpretation of bulk rotifer enzyme activities, we should take the bacterial contribution into account.
\end{abstract}

Key words: rotifers, phosphatase, $\beta$ - $N$-acetylhexosaminidase, enzyme localization

\section{INTRODUCTION}

Brachionus calyciflorus is a common species in freshwater ponds, lakes and reservoirs, almost cosmopolitan and often cultured for laboratory experiments. In our preceding study, B. calyciflorus was used in investigating digestive enzymes (Štrojsová \& Vrba 2007). Hydrolytic enzymes involved in rotifer digestive processes could be detected and/or measured either in rotifer homogenates or directly at the site of enzyme action in intact rotifers. Because non-axenic rotifer cultures are commonly used, the contribution of enzyme activities of organisms other than B. calyciflorus has to be considered.

Localizations of enzyme activities of $B$. calyciflorus were previously studied by the Fluorescently Labelled Enzyme Activity (FLEA) technique (Štrojsová \& Vrba 2007). The FLEA technique, together with image analysis software, can also be used for quantification of enzyme activity (Nedoma et al. 2003; S̆trojsová \& Vrba 2008). The fluorogenic $\operatorname{ELF}^{\circledR} 97$ substrates are soluble in water and could be ingested by the rotifers when feeding. After enzymatic hydrolysis, the non-fluorescent substrate turns into insoluble fluorescent ELF alcohol that precipitates and tags the enzyme activity outside or inside the rotifer body. The activity of phosphatase and $\beta-\mathrm{N}$-acetylhexosaminidase was observed mainly in the digestive tract, but was also observed at the corona and on the lorica of B. calyciflorus (Štrojsová \& Vrba 2007). While it is possible to hypothesize a digestive function of enzyme activity, its function within the corona and lorica is still unknown.
In our previous study (Štrojsová \& Vrba 2007), epizooic bacteria were not observed on the rotifer body stained with DAPI (Porter \& Feig 1980); however, epizooic bacteria were commonly observed on the epidermis of B. plicatilis (Kleinow 1993). Because of possible overlap of the fluorescence of ELF alcohol and DAPI, we were not completely convinced that the enzymatic activities were exclusively of rotifer origin (Štrojsová \& Vrba 2007). To solve this problem, we used a more sensitive method, scanning electron microscopy (SEM), to detect possible epizooic bacteria on the surface of $B$. calyciflorus. We inspected the same culture of $B$. calyciflorus which we used to study rotifer digestive enzymes.

\section{METHODS}

Brachionus calyciflorus Pallas, isolated from Lake Constance, was obtained from the Leibniz Institute of Freshwater Ecology and Inland Fisheries (Berlin, Germany) and cultured in 6-mL chambers of 12-well microtiterplates in Z/4 medium (Zehnder \& Gorham 1960). Stock cultures were diluted weekly $(1: 2$; culture/medium) and incubated at $19 \pm 1{ }^{\circ} \mathrm{C}$ under a $12: 12$ h light/dark regime. Rotifers were fed on Chlorella kessleri Fott et Novakova (Culture Collection of Algal Laboratory, Institute of Botany AS CR, Třeboň, Czech Republic) once a week.

B. calyciflorus was prepared for SEM according to Riemann et al. (2008). The rotifers were narcotized by water enriched with $\mathrm{CO}_{2}$, then killed by a small amount of $1 \%$ osmiumtetroxide $\left(1 \% \mathrm{OsO}_{4}\right.$ in $0.1 \mathrm{M}$ sodium cacodylate buffer). Finally, the rotifers were washed in 

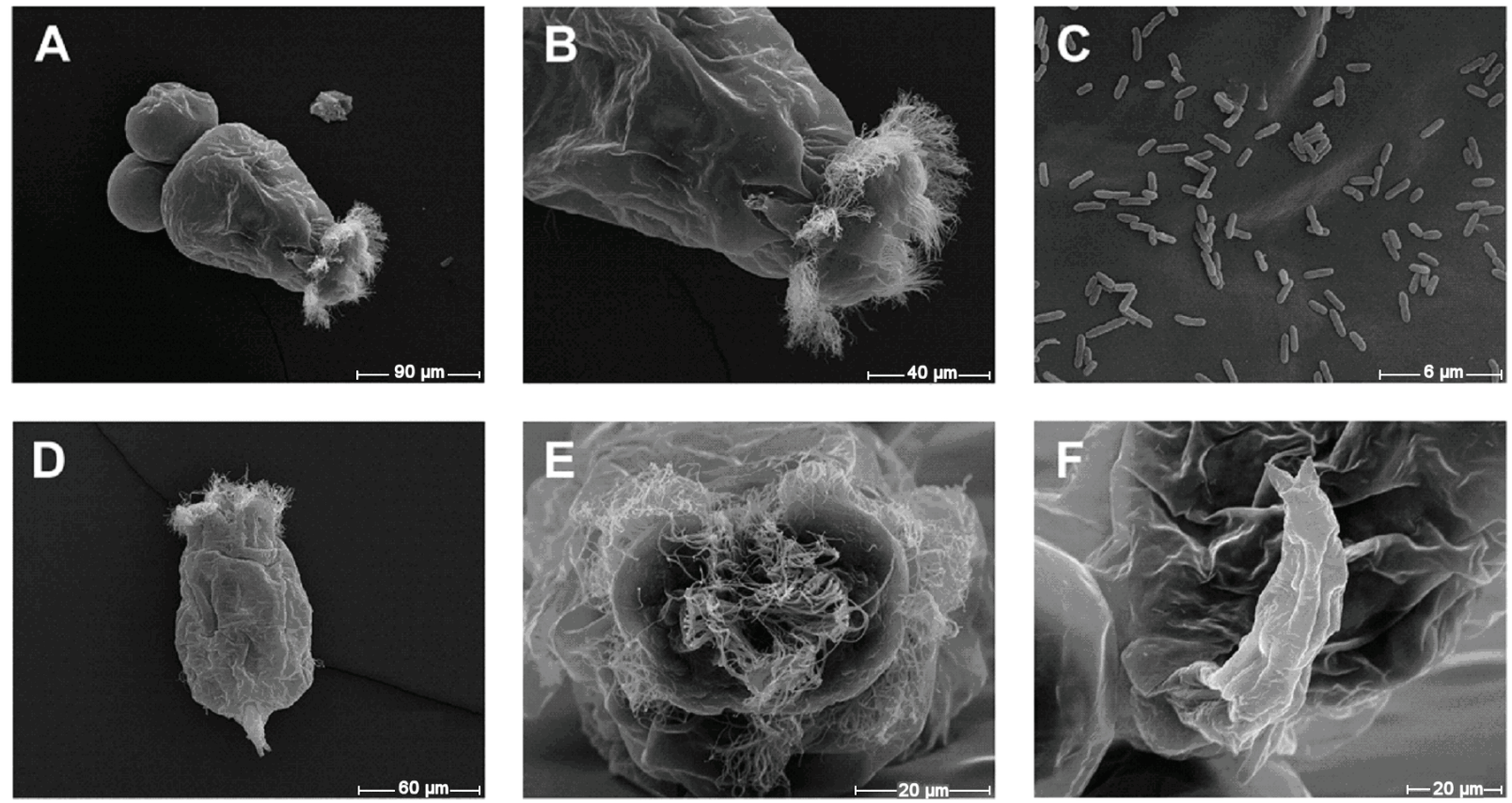

Fig. 1. Scanning electron micrographs of B. calyciflorus. B. calyciflorus with surface-attached epizooic bacteria (A), detail of the same individual of $B$. calyciflorus shows attached bacteria on the lorica but not at the corona (B), bacteria on the lorica $(C)$, young $B$. calyciflorus with a small numbers of bacteria (D), detail of corona, posterior epidermis and foot without bacteria $(\mathbf{E}, \mathbf{F})$.

distilled water and PAF fixative solution (Melone \& Ricci 1995) was added. The rotifers were dehydrated in an ethanol series starting with 5\% ethanol and ending with pure ethanol. After critical point-drying in a Teflon container, the rotifers were mounted on cover slips covered with a mixture of Tempfix ${ }^{\circledR}$ (Plano, Wetzlar, Germany) and chloroform. The cover slips were placed on an aluminium stub and finally covered with platinum. Samples with rotifers were examined using SEM (Hitachi S-3200N).

Epifluorescence images of $B$. calyciflorus with tagged enzyme activity were acquired using the FLEA technique. We examined B. calyciflorus individuals from the same culture as was used for SEM. Part of the rotifer culture was transferred into test tubes and either the fluorogenic ELF97 phosphate or ELF97 N-acetyl- $\beta$ D-glucosaminide was added (Molecular Probes, Eugene, OR, USA; 20 and $40 \mu \mathrm{mol} \mathrm{L} \mathrm{L}^{-1}$ final concentration, respectively) and incubated at $20^{\circ} \mathrm{C}$ in light. After a 3-h incubation, the samples were filtered through a membrane filter ( $12 \mu \mathrm{m}$ pore size) over a mild vacuum in a glass filter holder. The rotifers were inspected for the presence of ELF alcohol precipitates in an epifluorescence microscope (Olympus AX-70, Tokyo, Japan). We documented the locations of ELF alcohol labeling on images taken by a digital monochromatic camera (High Performance CCD Camera, COHU, San Diego, CA, USA), connected to a PC-based image analysis system (Lucia G/F 4.8, Laboratory Imaging, Prague, Czech Republic); for a detailed description see Nedoma et al. (2003). Images from epifluorescence microscopy, which show enzyme activities, were taken for comparison with SEM images.

\section{RESULTS AND DISCUSSION}

B. calyciflorus was examined by SEM for the presence of epizooic bacteria. We aimed to identify the true origin of phosphatase and $\beta$-N-acetylhexosaminidase activities at the rotifer corona and on the lorica that were detected in our previous investigation of digestive enzymes (Štrojsová \& Vrba 2007). The rotifers were in an excellent condition and were available in high numbers for SEM examination. We were aware that rotifers are sensitive to stress and/or disturbances and thus $B$. calyciflorus were prepared for SEM with a modified gentle technique to prevent the retraction of the rotifer body.

Epizooic bacteria were observed on the surface of rotifer lorica (Fig. 1 A-C). There was only one type of bacteria, $\sim 1.5 \mu \mathrm{m}$ long, which originated from the algal culture used for rotifer feeding. There were hundreds to thousands of attached bacteria on the adult rotifers in comparison to young individuals with only tens of bacterial cells (Fig. 1 D). Bacteria were not observed either on the B. calyciflorus corona or on its posterior epidermis and foot (Fig. 1 E, F). Most probably, the frequent contractions of head and foot are highly unfavorable for bacteria, which prefer other, more stable surfaces, e.g. lorica. On the other hand, Selmi (2001) observed filamentous bacteria attached by strands to the cell mem- 


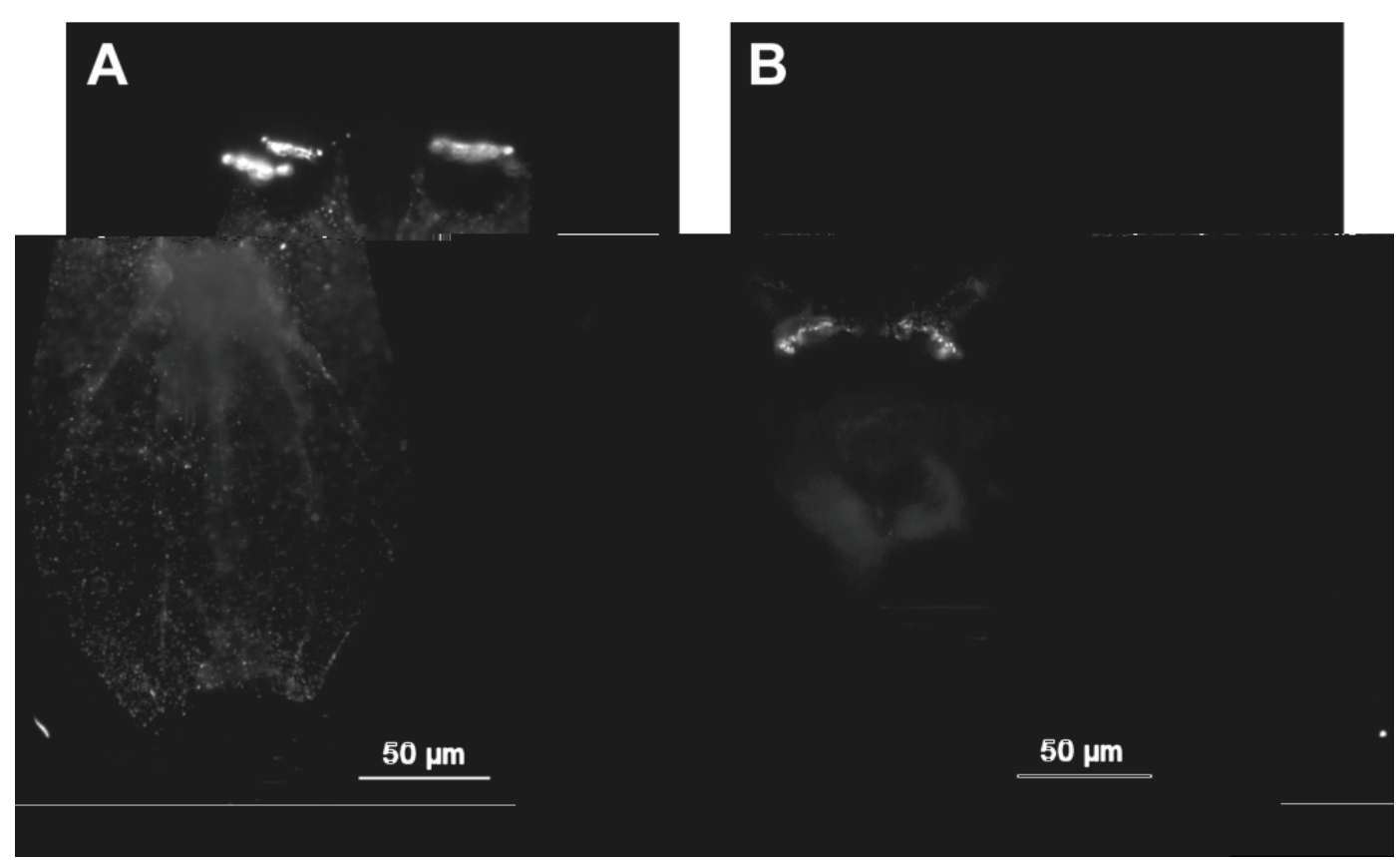

Fig. 2. Localization of phosphatase activities of B. calyciflorus visualized in an epifluorescence microscope using the FLEA technique; the white color indicates the site of enzyme activity (fluorescence of ELF alcohol precipitates). (A) Enzyme activity sites at the corona and on the lorica of grown rotifer and (B) enzyme activity sites at the corona of young rotifer.

brane of the ciliated buccal region of $B$. plicatilis. Epizooic bacteria were detected on the lorica and epidermis of B. plicatilis (Kleinow 1993). While Kleinow (1993) proposed that it was a sort of infection occurring due to the bad condition of the rotifer culture, we observed attached bacteria in a well-grown rotifer culture, i.e. rotifers with a high population growth rate and fecundity.

Phosphatase and $\beta$-N-acetylhexosaminidase activities were visualized by the FLEA technique at the corona and on the lorica (Fig. 2 A, B). Surface-attached bacteria with their own enzyme activities might affect the values and interpretation of the rotifer digestive enzyme activities. Since the volume of epizooic bacteria did not exceed more than $\sim 1 \%$ of the rotifer volume, the contribution of enzyme activity originating from bacteria to the bulk enzyme activity in the rotifer homogenate is likely to be negligible. On the other hand, the bacterial contribution could be significant, if rotifer digestive enzyme activity is measured by the FLEA technique and image analysis. Even though it is possible to focus the microscope precisely on the site of enzyme action, i.e. the digestive tract, the bulk enzyme activity of a particular rotifer might be overestimated due to ectoenzymes of bacteria attached to the rotifer surface. Moreover, whereas the dissolved ELF substrates are directly available for enzyme hydrolysis at the corona and on the lorica, ELF alcohol labeling might be delayed in the digestive tract due to slower uptake of the ELF substrate by rotifers (Štrojsová \& Vrba, 2007).

While the phosphatase and $\beta$-N-acetylhexosaminidase activities were detected at the corona of B. caly- ciflorus (Fig. 2), bacteria were never observed at the corona using SEM. We suggest that enzymes detected at the corona were secreted from pores, which penetrate across the integument of the corona in Brachionus (Yu $\&$ Cui 1997). By comparing rotifer images from SEM and the epifluorescence microscope, we conclude that it was most likely to be attached epizooic bacteria that produced the enzymes observed on the lorica of $B$. calyciflorus; however, the enzyme activities detected at the corona were most probably of pure rotifer origin.

\section{ACKNOWLEDGEMENTS}

This study was supported by the Czech Ministry of Education, Youth and Sports (project MSM 6007665801) and by the Grant Agency of ASCR (project AV0Z60170517). We thank R. Kort for her assistance with the SEM documentation, A. Štrojsová for her constructive comments on the manuscript and $\mathrm{P}$. Znachor for help with the graphic set-up of micrographs.

\section{REFERENCES}

Kleinow, W. 1993. Chemical studies on Brachionus plicatilis: hydrolytic enzymes, integument proteins and composition of trophy. Hydrobiologia, 255/256: 1-12.

Melone, G. \& C. Ricci. 1995. Rotatory apparatus in Bdelloids. Hydrobiologia, 313/314: 91-98.

Nedoma, J., A. Strojsová, J. Vrba, J. Komárková \& K. Šimek. 2003. Extracellular phosphatase activity of natural plankton studied with ELF97 phosphate: fluorescence quantification and labelling kinetics. Environ. Microbiol., 5: 462472 . 
Porter, K.G. \& Y.S. Feig. 1980. The use of DAPI for identifying and counting aquatic microflora. Limnol. Oceanogr., 25: 943-948.

Riemann, O., A. Kieneke \& W. H. Ahlrichs. (2008). Phylogeny of Dicranophoridae (Rotifera: Monogononta) - a maximum parsimony analysis based on morphological characters. J. Zool. Syst. Evol. Res.: (in press).

Selmi, G., R. Dallai, P. Lupetti \& B.A. Afzelius. 2001. Ectosymbiotic bacteria on ciliated cells of a rotifer. Tissue \& Cell, 33: 258-261.

Received: December 2008

Accepted: March 2009
Štrojsová, M. \& J. Vrba. 2007. Rotifer digestive enzymes: Direct detection using the ELF technique. Hydrobiologia, 593: 159-165.

Štrojsová, M., J .Sed’a, J. Nedoma \& J. Vrba. 2008. Diet quality impact on growth, reproduction and digestive activity in Brachionus calyciflorus. J. Plankton Res., 30: 11231131.

$\mathrm{Yu}$, J.P. \& S.J. Cui. 1997. Ultrastructure of the rotifer Brachionus plicatilis. Hydrobiologia, 358: 95-103.

Zehnder, A.A. \& P.R. Gorham. 1960. Factor influencing the growth of Microcystis aeruginosa Kütz. emend. Elenk. Can. J. Microbiol., 6: 645-660. 